\title{
Submucosal tunneling endoscopic myotomy of esophageal epiphrenic diverticulum
}

Esophageal epiphrenic diverticulum (EED) is an uncommon disease of the distal $10 \mathrm{~cm}$ of the thoracic esophagus. This motility disorder is associated with achalasia in over $60 \%$ of cases [1]. Large diverticula or those with significant symptoms are cured through diverticulectomy, myotomy, and fundoplication by open or minimally invasive surgical techniques [2]. Recently, Cai et al. reported four patients with EED who were treated by submucosal tunneling endoscopic septum division (STESD) [3]. This video case describes the treatment of EED using this novel technique ( $\triangleright$ Video 1$)$.

A 52-year-old man who was referred for dysphagia and regurgitation underwent upper endoscopy and esophagogram, both of which revealed a large diverticulum $10 \mathrm{~cm}$ above the cardia ( Fig.1a, \Fig.2a). Esophageal manometry showed a hypertonic esophagus.

A gastroscope with cap was used, and after the submucosal injection of methylene blue solution, a $1 \mathrm{~cm}$ transverse mucosal incision was made $3 \mathrm{~cm}$ proximal to the upper border of the diverticulum using a FlushKnife (Fujifilm, Tokyo, Japan). A submucosal tunnel was made by gentle thermoelectric dissection from the initial opening of the esophagus to the point at which it reached the stomach. The muscular septum was dissected along both sides to create an endoscopic window. Thereafter, the diverticular septum was divided along its entire length, and an extensive and complete myotomy was performed from the septum to the stomach. Finally, a rubber band ligature closed the mucosal incision. Intravenous ceftriaxone ( $2 \mathrm{~g}$ once daily) was continued for 3 days.

The patient experienced thoracic pain and subcutaneous emphysema in the upper chest and neck that resolved after a few days. A chest radiograph revealed a mild left pleural effusion 15 days after the procedure. Symptoms had totally resolved 15 days later.

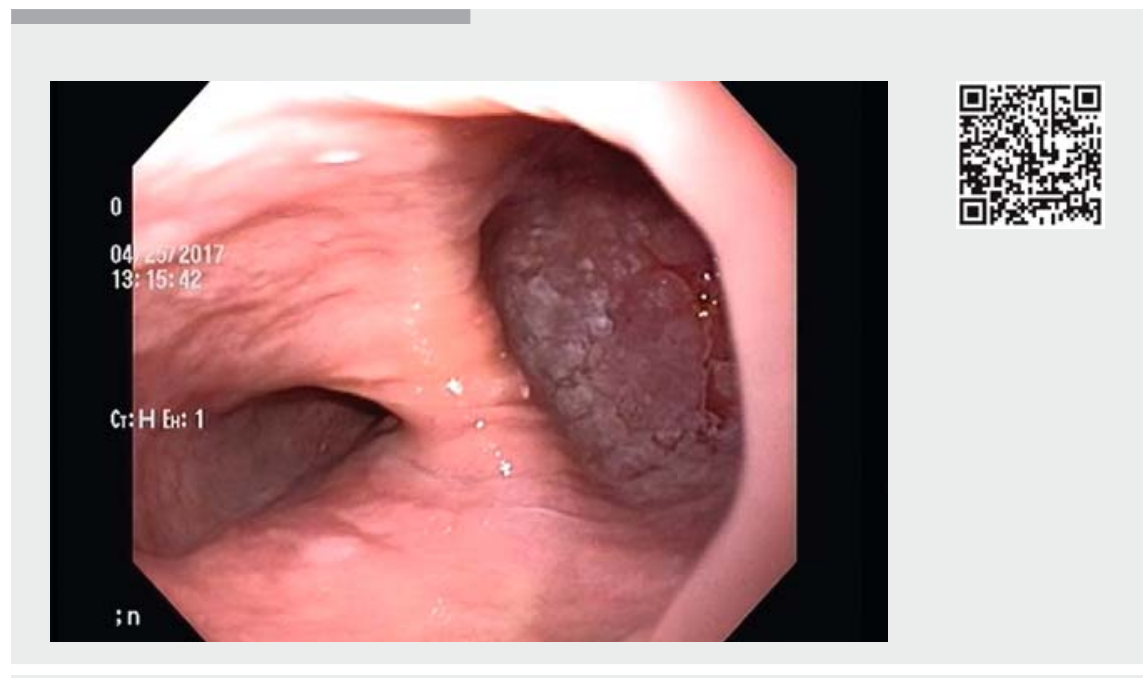

Video 1 The procedure of submucosal tunneling endoscopic septum division and esophageal myotomy from the diverticulum border to the point at which it reached the stomach.
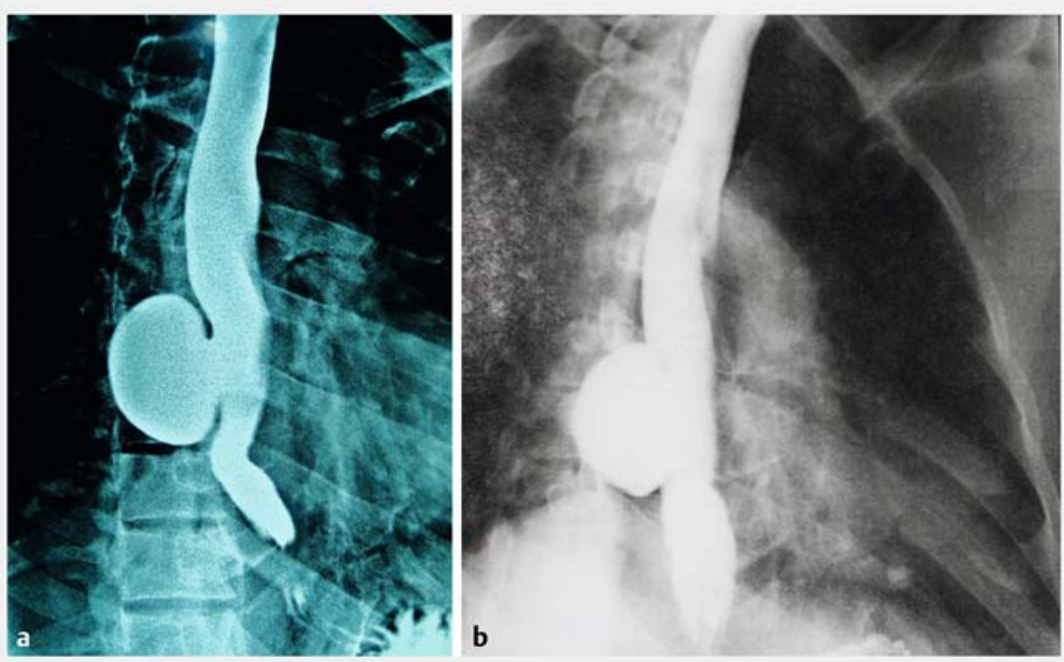

Fig. 1 Esophagogram showing the esophageal epiphrenic diverticulum. a Before submucosal tunneling endoscopic septum division (STESD). b 90 days after STESD.

Despite the complete septum section, imaging revealed an intact diverticulum and severe esophagitis 90 days after STESD ( Fig. $\mathbf{1}$ b, $>$ Fig. $\mathbf{2}$ b, c). Further studies that include more patients and have longer follow-up are required to comprehend the role of STESD in the management of EED.

Endoscopy_UCTN_Code_TTT_1AO_2AN 

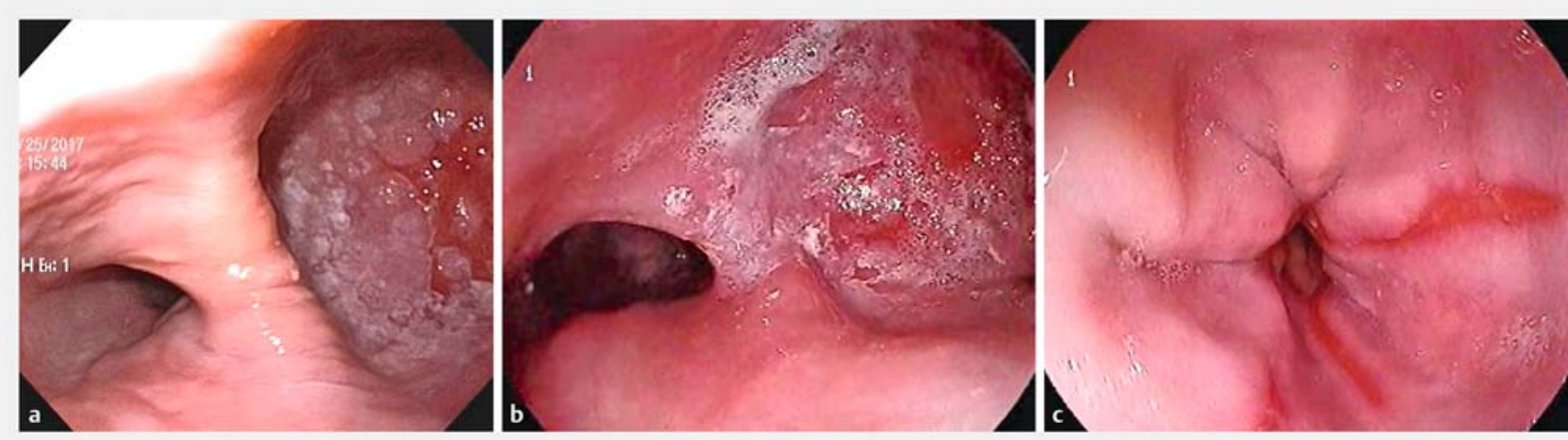

Fig. 2 Esophagoscopy. a Before submucosal tunneling endoscopic septum division (STESD). b 90 days after STESD. c Severe esophagitis 90 days after STESD.

\section{Competing interests}

None

The authors

Antônio Carlos Conrado' ${ }^{1}$ Luiz Eduardo Correia Miranda ${ }^{2}$, Ana Clara Miranda², Diego Laurentino Lima²

1 Division of Endoscopy, Restauração Hospital, Recife, Pernambuco, Brazil

2 Department of General Surgery, Hospital Oswaldo Cruz, Pernambuco University, Recife, Pernambuco, Brazil

\section{Corresponding author}

\section{Luiz Eduardo Correia Miranda, MD}

Department of General Surgery, Hospital

Oswaldo Cruz, Rua Arnóbio Marques, 310,

Bairro de Santo Amaro, Recife, 50.100-130, Brazil

Fax: +55-81-31833520

lecmiranda@gmail.com

\section{References}

[1] Sonbare D]. Pulsion diverticulum of the oesophagus: more than just an out pouch. Indian I Surg 2015; 77: 44-48

[2] Andolfi C, Wiesel O, Fisichella P. Surgical treatment of epiphrenic diverticulum: technique and controversies. J Laparoendosc Adv Surg Tech A 2016; 26: 905-910

[3] Cai M, Xu M, Li Q et al. [Preliminary results of submucosal tunneling endoscopic septum division in the treatment of esophageal diverticulum.] [Article in Chinese]. Zhonghua Wei Chang Wai Ke Za Zhi 2017; 20: 530 534

\section{Bibliography}

DOI https://doi.org/10.1055/s-0043-121567

Published online: 14.11.2017

Endoscopy 2018; 50: E44-E45

(c) Georg Thieme Verlag KG

Stuttgart · New York

ISSN 0013-726X

\section{ENDOSCOPY E-VIDEOS}

https://eref.thieme.de/e-videos

回的回 Endoscopy E-Videos is a free access online section, reporting 回程: on interesting cases and new techniques in gastroenterological endoscopy. All papers include a high quality video and all contributions are freely accessible online.

This section has its own submission website at

https://mc.manuscriptcentral.com/e-videos 